\title{
Optimal Reallocation of Generators using Line Utilization Factor and L-Index with UPFC
}

\author{
Sravana Kumar Bali, G.V.Nagesh Kumar, Akanksha Mishra, P.V.S.Sobhan
}

\begin{abstract}
In the electrical industry, globalization and privatization have greatly increased competition. Therefore, it has become completely necessary to make full use of existing power assets. In this paper, a technique was proposed in the presence of UPFC to optimize the sizing of generators with Krill Herd algorithm. The UPFC is based on an index incorporating both the $L$-index and the LUF index. For tuning the generators, a multi-objective function has been selected. The multi-objective feature consists of deviation of voltage, cost of active generation of power and loss of transmission line. This approach was tested and implemented for regular loading and extreme network conditions due to line failure on an IEEE 30 bus system.
\end{abstract}

Keywords: Optimal Reallocation; UPFC; Krill Herd Algorithm; Voltage Stability

\section{INTRODUCTION}

$\mathrm{O}$ ptimal power flow or optimal generator reallocation consists of optimizing an objective function when operational constraints are present. To solve the OPF problem, a lot of methods have been developed so far. In [1] Zhang et al. suggested a revised method for solving OPF based on multi-objective evolutionary algorithms. For obtain a uniformly distributed pareto-optimal solution, an adapted Tchebycheff decomposition approach was used. A solution to the power system's optimum energy flow problem was obtained using various methods such as Improved Colliding Bodies Optimization algorithm [2], Particle swarm optimization with aging leader and challenger [3], adaptive group search optimization [4].

FACTS components have a very important role in further enhancing the impact of the power systems solution on the OPF problem. Mahdad and Srairi [5] used the adaptive flower pollination algorithm combined with SVC to resolve the OPF in the case of failures in the generating units. UPFC is a better FACTS tool that has been used to mitigate transmission losses and network operating costs [6-7], power system loadability, congestion management and various other applications. For the optimum power flow with UPFC, the Krill Herd Algorithm was used in this article. UPFC has been put in the process using LUF and L-index. For a poly-objective feature,

\footnotetext{
Revised Manuscript Received on December 13, 2019.

\# Correspondence Author

B.Sravana Kumar ${ }^{\#}$, EEE department, GITAM Deemed to be University, Visakhapatnam, INDIA. Email: sravanbali@gmail.com

G.V.Nagesh Kumar, EEE department, JNTUA College of Engineering Pulivendula, INDIA. Email: drgvnk14@gmail.com

Akanksha Mishra, EEE department, Vignan's Institute of Engineering for Women, Visakhapatnam, INDIA Email: misakanksha@gmail.com

P.V.S.Sobhan, EEE department, Vignan University, Guntur,A.P., INDIA. Email:pvssobhan@gmail.com
}

specifically decreasing deviation of voltage cost of active generation of power and loss of transmission line. The optimal tuning of generators was achieved. True and imaginary power values and bus voltage limits are taken as optimization requirements. To prove the validity of the novel procedure, the results of optimum tuning without and with UPFC were compared.

\section{II.INDEX FOR PLACEMENT OF UPFC}

A. L-index :The expression for L- index is given in Equation (1). $\mathrm{F}_{\mathrm{pq}}$ indicates complex parameters, $\mathrm{V}_{\mathrm{q}}$ indicates magnitude of voltage at bus $q$ and $V_{j}$ indicates magnitude of voltage at bus $\mathrm{p}$.

$$
\text { Lindex }=\left|1-\sum_{q=1}^{g} F_{p q} \frac{V_{q}}{V_{p}}\right|
$$

B. Line Utilization Factor (LUF): LUF is an index used for determining the congestion of the transmission lines as given in equation 4 .

$$
L U F=\frac{M V A_{p q}}{M V A_{p q}^{\max }}
$$

Objective function is presented by Equation (3).

$$
\operatorname{Min} \mathrm{O}=\mathrm{Min}\left(\mathrm{W}_{1} * \mathrm{O}_{1}+\mathrm{W}_{2} * \mathrm{O}_{2}+\mathrm{W}_{3} * \mathrm{O}_{3}\right)
$$

Where,

$\mathrm{O}_{1}$ is the Fuel cost given by

$$
\mathrm{O}_{1}=\min \left(\sum_{i=1}^{n g}\left[a_{i}+b_{i} P_{G i}+c_{i} P_{\mathrm{Gi}}^{2}\right]\right)
$$

$\mathrm{O}_{2}$ is the Real power loss

$$
\mathrm{O}_{2}=\min \left(\sum_{i=1}^{n t l} \operatorname{real}\left(S_{\mathrm{pk}}^{\mathrm{q}}+S_{\mathrm{kp}}^{\mathrm{q}}\right)\right)
$$

$\mathrm{O}_{3}$ is the Voltage deviation

$$
\mathrm{O}_{3}=\min (V D)=\min \left(\sum_{k=1}^{N b u s}\left|V_{k}-V_{\mathrm{k}}^{\mathrm{ref}}\right|^{2}\right)
$$


Optimal Reallocation of Generators using Line Utilization Factor and L-Index with UPFC

\section{KriLl Herd Algorithm}

Algorithm represented in the form flow chart as shown below

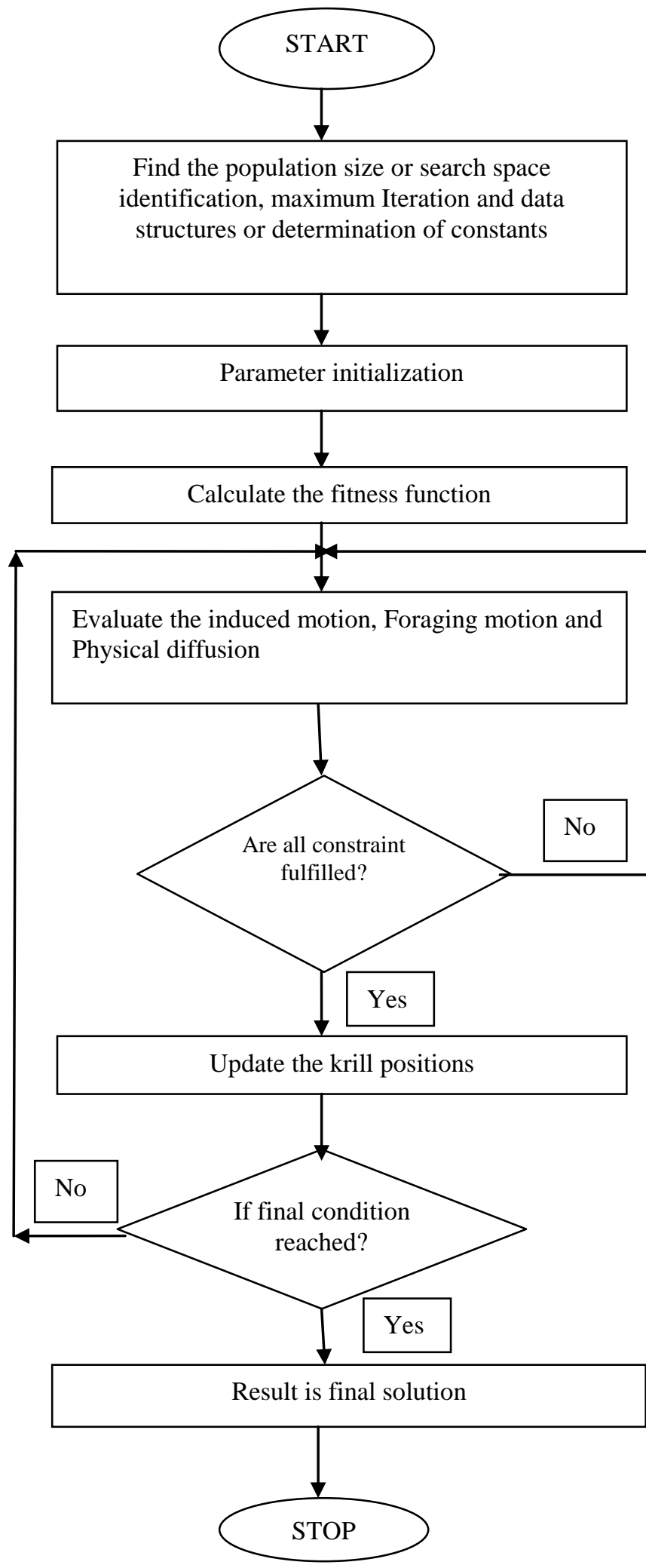

Fig.1 Krill Herd Algorithm Flowchart

\section{PROPOSED METHODOLOGY}

The procedure for the proposed methodology has been mentioned in Fig. 2

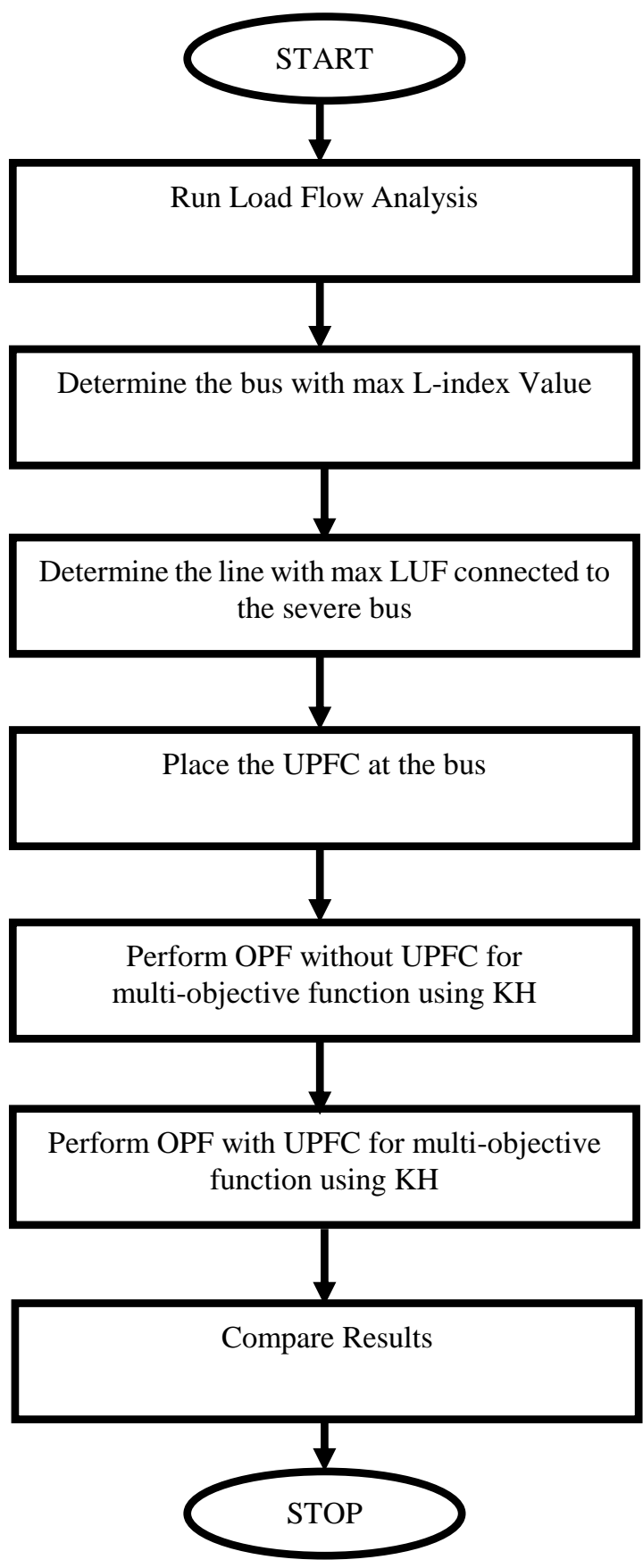

Fig.2 Flow Chart for the illustration of the proposed methodology

\section{RESULTS AND DISCUSSION}

On an IEEE 30 bus scheme, the suggested procedure is implemented. The review of the NR load stream for the IEEE 30 bus structure is completed. From Fig 3, it is seen that bus number 30 has a total L-index value of 0.0895 p.u. And thus it is considered the system's most extreme train. Two lines, namely 27-30 and 29-30, are linked to bus number 30 .

From Fig, it is observed. 4, that the maximum LUF value of 27-30 is 0.0367 p.u. respectively. Therefore, UPFC put in the IEEE 30 bus structure at bus 30 and line 27-30. The objective function analysis was provided by combining different NR and NK values in Fig. 5. 
It is found that Number of runs $=20=$ Number of krill's, which was considered for the analysis,

presents the objective function's least average and best value. The total active generated power by the scheme and individual generator whose actual and reactive power loss, deviation of voltage and cost of active power generation are compared for OPF using and not using UPFC conditions in Table 1. It is observed that the generation is tuned at the different generators to reduce the overall device output. With OPF using UPFC, actual and reactive power loss, voltage variance and cost of generation are decreased. In Fig 6, the actual power loss is contrasted in the 30 bus structure. It is seen that the actual power loss decreases from 10.78 MW to 5.17 MW after conducting OPF with UPFC.

Study of contingency for the IEEE bus structure is carried out and it is noted that elimination of 27-28 induces peak pressure in bus 30 representedd by the highest L-index result of 0.4522 p.u as illustrated in Table 2. Table 3 reveals that line 27-30 is the severe-most line of contingency for line 27-28. For the analysis, therefore, single line contingency for 27-28 and UPFC was considered for bus 30 and line 27-30.

The actual power output, the actual loss of power, the network reactive power loss under different system conditions and the

$* \mathrm{NR}=$ Number of runs $\mathrm{NK}=$ Number of Krills

generation costs the individual generators are measured in of 0.4522 p.u as illustrated in Table 2. Table 3 reveals that line 27-30 is the severe-most line of contingency for line 27-28. For the analysis, therefore, single line contingency for 27-28 and UPFC was considered for bus 30 and line 27-30.

The actual power output, the actual loss of power, the network reactive power loss under different system conditions and the generation costs the individual generators are measured in Table 4 under usual and emergency conditions. In both normal and contingency conditions, the OPF using UPFC is found to be the best result. The voltage report of the use and non-use UPFC 30 bus system was compared in Fig.7.

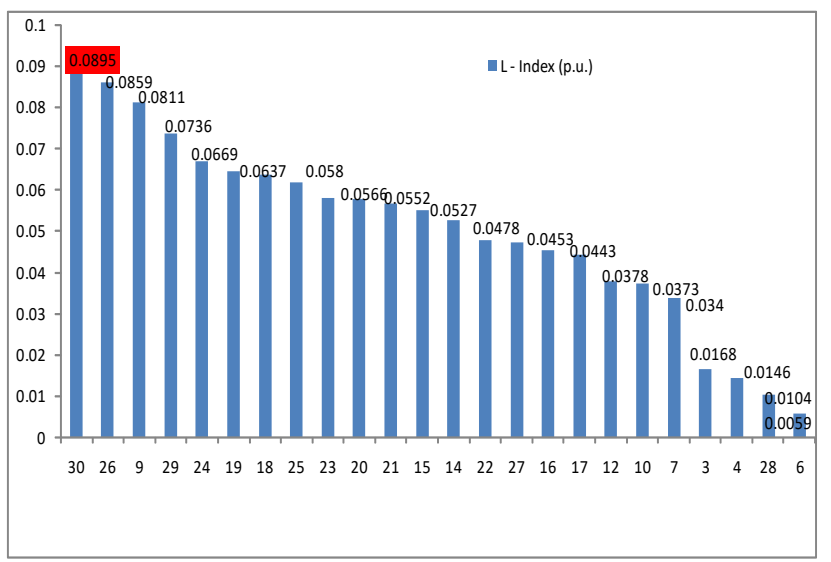

Fig. 3 Feeble bus in IEEE 30 bus

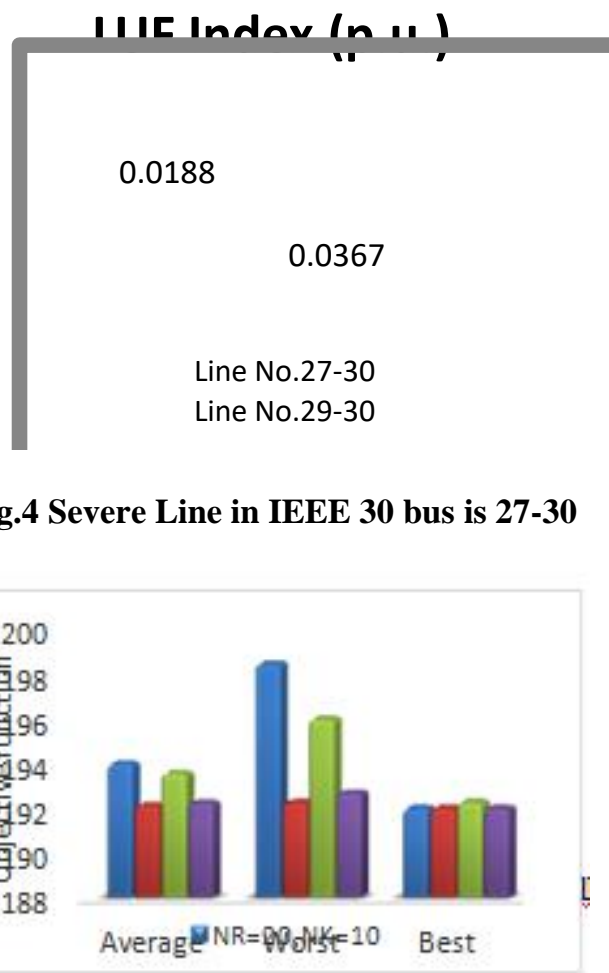

Fig.5 Analysis of Objective Function value by varying Krill Herd Parameters

Table I: A 30 bus system result comparison availing KH-OPF using UPFC and not using UPFC

\begin{tabular}{|c|c|c|c|}
\hline \multicolumn{2}{|c|}{ Comparison Parameters } & $\begin{array}{l}\text { KH-OPF } \\
\text { not using } \\
\text { UPFC }\end{array}$ & $\begin{array}{l}\text { KH-OPF } \\
\text { using UPFC }\end{array}$ \\
\hline \multirow{6}{*}{$\begin{array}{l}\text { Real power } \\
\text { generation } \\
\text { (MW) }\end{array}$} & PG1 & 115.517 & 87.0542 \\
\hline & PG2 & 50 & 50 \\
\hline & PG5 & 37.37 & 20.8158 \\
\hline & PG8 & 37 & 39.24574 \\
\hline & PG11 & 40.124 & 41.46105 \\
\hline & PG13 & 10 & 50 \\
\hline \multicolumn{2}{|c|}{$\begin{array}{l}\text { Total Active generation of } \\
\text { Power(MW) }\end{array}$} & 290.011 & 288.5768 \\
\hline \multicolumn{2}{|c|}{ Total active power loss (MW) } & 6.618261 & 5.17686 \\
\hline \multicolumn{2}{|c|}{ Total reactive power loss (MVAR) } & 15.9 & 4.462 \\
\hline \multicolumn{2}{|c|}{ Deviation of Voltage (p.u.) } & 1.8355 & 0.30959 \\
\hline \multicolumn{2}{|c|}{$\begin{array}{l}\text { Cost of Active generation of } \\
\text { Power }(\$ / h)\end{array}$} & 1365.33 & 1220.2 \\
\hline
\end{tabular}


Optimal Reallocation of Generators using Line Utilization Factor and L-Index with UPFC

Table IV: COMPARISON OF REAL GENERATION AND COST FOR WITHOUT CONTINGENCY \& CONTINGENCY

5.17

6.61

6.63

KH-OPF without UPFC

KH-OPF with UPFC

Fig.6 Result of different methods in terms of power loss comparison

Table II: Feeble bus in IEEE 30 Bus Structure

\begin{tabular}{|c|c|c|c|}
\hline RANK & Bus No & $\begin{array}{c}\text { Line } \\
\text { Outage }\end{array}$ & L-Index \\
\hline 1 & 30 & $27-28$ & 0.4522 \\
\hline 2 & 19 & $9-10$ & 0.1918 \\
\hline 3 & 30 & $27-30$ & 0.1793 \\
\hline 4 & 29 & $27-29$ & 0.1613 \\
\hline 5 & 14 & $4-12$ & 0.1591 \\
\hline 6 & 21 & $10-21$ & 0.1416 \\
\hline 7 & 26 & $25-27$ & 0.1375 \\
\hline 8 & 20 & $10-20$ & 0.1341 \\
\hline 9 & 30 & $6-28$ & 0.1298 \\
\hline 10 & 19 & $19-20$ & 0.117 \\
\hline 11 & 17 & $10-17$ & 0.1167 \\
\hline 12 & 30 & $29-30$ & 0.1163 \\
\hline 13 & 30 & $3-4$ & 0.1151 \\
\hline 14 & 30 & $4-6$ & 0.1041 \\
\hline 15 & 26 & $10-22$ & 0.102 \\
\hline 16 & 26 & $22-24$ & 0.102 \\
\hline 17 & 30 & $6-10$ & 0.0938 \\
\hline 18 & 30 & $12-15$ & 0.0938 \\
\hline 19 & 30 & $23-24$ & 0.0934 \\
\hline 20 & 30 & $21-23$ & 0.0921 \\
\hline 21 & 30 & $12-14$ & 0.0907 \\
\hline 22 & 30 & $12-16$ & 0.0904 \\
\hline 23 & 30 & $15-18$ & 0.0902 \\
\hline 24 & 30 & $14-15$ & 0.0898 \\
\hline 25 & 30 & $18-19$ & 0.0898 \\
\hline 26 & 30 & $15-23$ & 0.0898 \\
\hline 27 & 30 & $16-17$ & 0.0894 \\
\hline 28 & 30 & $6-7$ & 0.0867 \\
\hline 29 & 30 & $6-9$ & 0.0857 \\
\hline 30 & 30 & $24-25$ & 0.0823 \\
\hline
\end{tabular}

Table III: SEVERE LINE IN IEEE 30 BUS SYSTEM

\begin{tabular}{|c|c|c|c|}
\hline \multirow[t]{2}{*}{ RANK } & \multicolumn{2}{|c|}{$\begin{array}{c}\text { LINE } \\
\text { CONNECTED }\end{array}$} & \multirow{2}{*}{$\begin{array}{c}\text { LUF } \\
\text { Value }\end{array}$} \\
\hline & FB & TB & \\
\hline 1 & 27 & 30 & 0.0379 \\
\hline 2 & 29 & 30 & 0.0191 \\
\hline
\end{tabular}

With UPFC placed at 27-30

\begin{tabular}{|c|c|c|c|c|}
\hline \multirow[b]{2}{*}{$\begin{array}{l}\text { Loading } \\
\text { Condition }\end{array}$} & \multirow{2}{*}{\multicolumn{2}{|c|}{ Parameter }} & \multicolumn{2}{|c|}{$\mathrm{KH}$} \\
\hline & & & \multirow{2}{*}{$\begin{array}{c}\begin{array}{c}\text { KH-OPF } \\
\text { not using } \\
\text { UPFC }\end{array} \\
115.517\end{array}$} & $\begin{array}{c}\text { KH OPF } \\
\text { using } \\
\text { UPFC }\end{array}$ \\
\hline \multirow{10}{*}{$\begin{array}{c}\text { Without } \\
\text { Contingency }\end{array}$} & \multirow{6}{*}{$\begin{array}{c}\text { Real power } \\
\text { generation } \\
\text { (MW) }\end{array}$} & PG1 & & 87.0542 \\
\hline & & PG2 & 50 & 50 \\
\hline & & PG5 & 37.37 & 20.8158 \\
\hline & & PG8 & 37 & 39.24574 \\
\hline & & PG11 & 40.124 & 41.46105 \\
\hline & & PG13 & 10 & 50 \\
\hline & \multicolumn{2}{|c|}{$\begin{array}{l}\text { Total Active } \\
\text { generation of power } \\
\text { (MW) }\end{array}$} & 290.011 & 288.5768 \\
\hline & \multicolumn{2}{|c|}{$\begin{array}{l}\text { Total Active power } \\
\text { losses (MW) }\end{array}$} & 6.618261 & 5.17686 \\
\hline & \multicolumn{2}{|c|}{$\begin{array}{l}\text { Total reactive power } \\
\text { loss (MVAR) }\end{array}$} & 15.9 & 4.462 \\
\hline & \multicolumn{2}{|c|}{$\begin{array}{l}\text { Total cost of Active } \\
\text { power generation }(\$ / \mathrm{hr})\end{array}$} & 1365.33 & 1220.2 \\
\hline \multirow{6}{*}{$\begin{array}{c}\text { With } \\
\text { Contingency }\end{array}$} & \multirow{6}{*}{$\begin{array}{l}\text { Real power } \\
\text { generation } \\
(\mathrm{MW})\end{array}$} & PG1 & 103.89 & 89.1579 \\
\hline & & PG2 & 50 & 50 \\
\hline & & PG5 & 34.086 & 21.69174 \\
\hline & & PG8 & 47.99 & 38.80698 \\
\hline & & PG11 & 47.22 & 40.97791 \\
\hline & & PG13 & 10 & 50 \\
\hline \multirow[t]{4}{*}{$27-28$} & \multicolumn{2}{|c|}{$\begin{array}{l}\text { Total Active } \\
\text { generation of power } \\
\text { (MW) }\end{array}$} & 293.186 & 290.6345 \\
\hline & \multicolumn{2}{|c|}{$\begin{array}{l}\text { Total Active power } \\
\text { losses (MW) }\end{array}$} & 9.79 & 7.23 \\
\hline & \multicolumn{2}{|c|}{$\begin{array}{l}\text { Total reactive power } \\
\text { loss (MVAR) }\end{array}$} & 26.16 & 8.16 \\
\hline & \multicolumn{2}{|c|}{$\begin{array}{l}\text { Total cost of Active } \\
\text { power generation }(\$ / \mathrm{hr})\end{array}$} & 1374.91 & 1327.5 \\
\hline
\end{tabular}

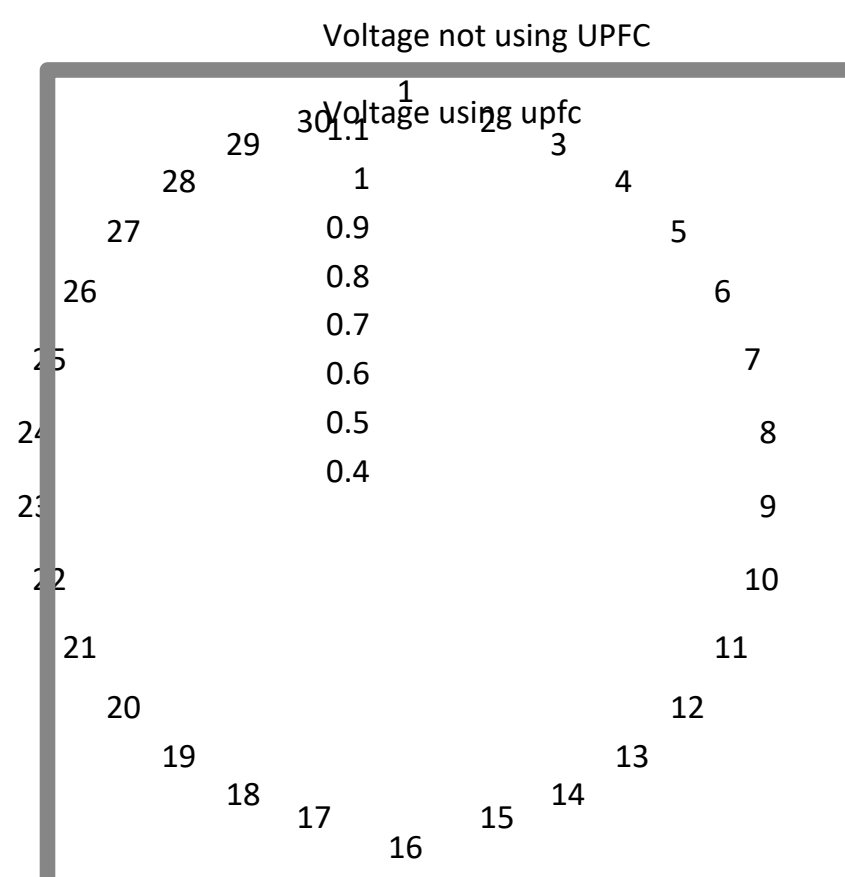

Fig. 7. IEEE30 bus system with contrast of bus voltages with KH- OPF using UPFC and not using UPFC

Published By:

Blue Eyes Intelligence Engineering

\& Sciences Publication 


\section{CONCLUSION}

- Optimal power flow method with UPFC was suggested in this work to address the instability of voltage problems in power network and loss lessening.

- A multi-objective feature was considered for this reason, namely reducing the actual power loss, voltage deviation and reduction of fuel costs.

- UPFC was optimally configured depending on L-index and LUF in the process.

- UPFC and generator parameters are designed using the Krill herd algorithm.

- The suggested approach for the standard and n-1 contingency IEEE 30 bus structure was tested.

- Using UPFC, OPF was seen to be best result for enhancing the performance of the power system as shown by improving the power network parameter results.

\section{REFERENCES}

1. Zhang, Qinghui Tang, Daxiang Deng, Yalin Chen, "A modified MOEA/D approach to the solution of multi-objective optimal power flow problem", Appl.Soft Comp.J. 2016, in press.

2. Bouchekara, A.E. Chaib, M.A. Abido, R.A. El-Sehiemy, 2016,"Optimal power flow using an Improved Colliding Bodies Optimization algorithm", Appl.Soft Comp.J.42, 119-131.

3. Rudra Pratap Singh, V. Mukherjee, S.P. Ghoshal, 2016, "Particle swarm optimization with an aging leader and challengers algorithm for the solution of optimal power flow problem", Appl.Soft Comp.J. 40, 161-177.

4. Narges , Mehrdad Tarafdar Hagh , Saeed Teimourzadeh, 2016"Adaptive group search optimization algorithm for multi-objective optimal power flow problem", Appl.Soft Comp.J. 38, 1012-1024.

5. Mahdad, K. Srairi, 2016, "Security constrained optimal power flow solution using new adaptive partitioning flower pollination algorithm", Appl.Soft Comp.J. 46, 501-522.

6. Biplab, Vikash Kumar Gupta, Sanjay Kumar, 2014, "UPFC with series and shunt FACTS controllers for the economic operation of a power system", Ain Shams Engineering Journal. 5(3), 775-787.

7. Shaheen, G.I. Rashed, S.J. Cheng, 2010 "Application and comparison of computational intelligence techniques for optimal location and parameter setting of UPFC", Engineering Applications of Artificial Intelligence. 23(2), 203-216.

\section{AUTHORS PROFILE}

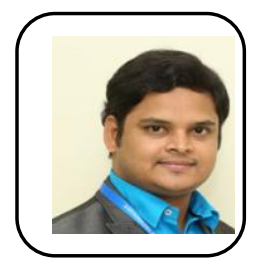

Sravana kumar Bali working as Assistan Professor in EEE Dept., GITAM, Vizag, A.P, India. He received his $\mathrm{PhD}$ from JNTU Kakinada.His area of interests are Power Systems, Contingency analysis, Algorithms and FACTS Devices.

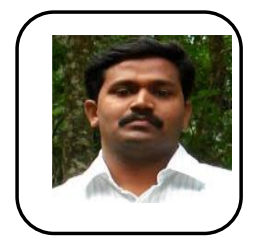

G.V. Nagesh Kumar graduated from GITAM, ME from, Andhra University, Visakhapatnam and $\mathrm{PhD}$ from JNTU, Hyderabad. He is presently working as professor and HOD in the EEE, JNT University, Pulivendula, A.P, India. His research interests include GIS, fuzzy logic and ANN, distributed generation, Partial Discharge Studies and Bearing less drives. He published more than 175 papers in reputed journals.

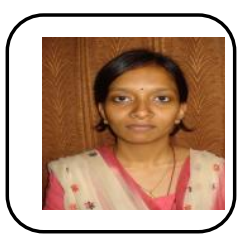

Akanksha Mishra was born in Cuttack, India in 1982. She received her $\mathrm{PhD}$ from Gandhi Institute of Technology and Management, Visakhapatnam, India. Her research interests are FACTS devices, Power Electronics and power system stability. She has published several research papers in national and international conferences.

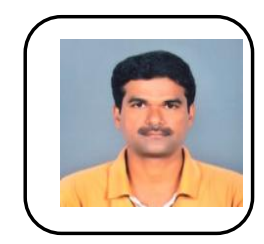

Polamraju.V.S.Sobhan received the B.Tech degree in Electrical and Electronics Engineering from SVHCE, Machilipatnam in 1999 and M.E degree from Andhra University, Visakhapatnam in 2002 $\mathrm{He}$ is presently working in the Department of EEE, VFSTR University, Guntur, India. His research interests include Intellegent Controllers Design, Active Magnetic Bearings and Bearingless drives 